\title{
EXPRESSÃO DOS ANTÍGENOS ABH E LEWIS NA GASTRITE CRÔNICA E ALTERAÇÕES PRÉ-NEOPLÁSICAS DA MUCOSA GÁSTRICA
}

\author{
Délia Cristina Figueira AGUIAR ${ }^{1}$, Tereza Cristina Oliveira CORVELO $^{1}$, Marialva ARAÚJO ${ }^{2}$, \\ Ermelinda Moutinho da CRUZ $^{2}$, Samiry DAIBES ${ }^{3}$ e Mônica Baraúna de ASSUMPÇÃO ${ }^{4}$.
}

RESUMO - Racional - A aderência do Helicobacter pylori à mucosa gástrica humana é pré-requisito para sua colonização e o desenvolvimento da gastrite crônica. Os antígenos de grupos sangüíneos, presentes no muco gástrico, são descritos como prováveis receptores da bactéria neste epitélio. A expressão alterada destes antígenos está associada ao desenvolvimento do câncer gástrico. Objetivos - Verificar a ocorrência do Helicobacter pylori e a distribuição da expressão dos antígenos ABH e Lewis correlacionada com as alterações histopatológicas de pacientes com gastrite crônica. Pacientes e Métodos - Analisaram-se 63 amostras de sangue, saliva e biopsias gástricas de pacientes com gastrite crônica através das técnicas dot-blot-ELISA, imunoperoxidase indireta e colorações do Gram modificado e hematoxilina-eosina. Resultados - Não foram encontradas associações significativas entre a presença da bactéria e os fenótipos de grupos sangüíneos $\mathrm{ABH}$, Lewis e Secretor. Na maioria dos pacientes, a expressão dos antígenos $\mathrm{ABH}$ e Lewis, estava restrita principalmente ao epitélio foveolar da mucosa gástrica, concordando com a expressão ao nível salivar. A expressão inapropriada desses antígenos ocorria sempre na infecção pelo Helicobacter pylori e/ou alterações pré-neoplásicas da mucosa gástrica. Em áreas com metaplasia intestinal foi observada a redução da reatividade para os antígenos $\mathrm{H}$ e Le ${ }^{\mathrm{b}}$, e principalmente o aumento de Le ${ }^{\mathrm{a}}$. Conclusão - Alterações no padrão de glicosilação destes antígenos refletem diferentes estágios de diferenciação celular e são marcadores potenciais na avaliação diagnóstica e prognóstica das patologias gástricas.

DESCRITORES - Helicobacter pylori. Infecções por helicobacter. Gastrite. Grupos sangüíneos.

\section{INTRODUÇÃO}

As gastrites são alterações histológicas da mucosa gástrica onde se observa infiltrado de células inflamatórias ${ }^{(32)}$. A inflamação pode ser aguda, crônica ou apresentar formas especiais. A gastrite crônica bacteriana que está associada à infecção pela bactéria Helicobacter pylori, é o tipo de maior freqüência. Esta bactéria é também considerada um dos agentes causadores da úlcera péptica e atua como co-fator na etiologia das malignidades gástricas.

A bactéria $H$. pylori coloniza especificamente a mucosa gástrica e as microvilosidades gástricas das células epiteliais.
Os mecanismos moleculares que intermediam a inflamação e as doenças ulcerativas em resposta à infecção pela bactéria não estão totalmente compreendidos, porém sua erradicação leva à cura da doença ulcerosa e também à redução na taxa de recurrência. Além do H. pylori, muitos outros fatores ambientais (álcool, fumo, dieta, etc.) e genéticos (grupos sangüíneos, complexo principal de histocompatibilidade, etc.) estão interelacionados na etiologia dessas doenças ${ }^{(31)}$.

A taxa de infecção populacional pelo $H$. pylori apresenta uniformidade relacionada ao grau de desenvolvimento dos países $^{(16)}$ : nos desenvolvidos, a taxa varia entre $25 \%$ a $50 \%$, enquanto naqueles em desenvolvimento está em torno de $70 \%$ -

\footnotetext{
Trabalho realizado no Departamento de Genética, Centro de Ciências Biológicas da Universidade Federal do Pará, Belém, PA.

${ }^{1}$ Departamento de Genética, Centro de Ciências Biológicas, Universidade Federal do Pará; ${ }^{2}$ Departamento de Anatomia Patológica, Centro de Ciências da Saúde, Universidade Federal do Pará; ${ }^{3}$ Hospital Universitário Betina de Ferro e Souza, Setor de Endoscopia, Universidade Federal do Pará; Hospital Universitário João de Barros Barreto, Setor de Endoscopia, Belém, PA.

Endereço para correspondência: Dra. Délia Cristina Figueira Aguiar - Av. Júlio César, Vila Maracangalha, casa 107 - 66613-010 - Belém, PA
} 
90\%. Em Belo Horizonte, MG, COELHO et al. ${ }^{(6)}$ descreveram que, em 51 pacientes sintomáticos, a prevalência da infecção pelo $H$. pylori foi de $80 \%$. Em Belém, PA, NETO ${ }^{(18)}$ encontrou prevalência de $57,14 \%$ da bactéria, enquanto que $\mathrm{SAGICA}^{(24)}$ encontrou taxa superior a $70 \%$ em diferentes amostras de pacientes com gastrite crônica.

Os prováveis receptores do $H$. pylori no epitélio gástrico são carboidratos das mucinas gástricas, que têm papel primordial na proteção da mucosa gástrica. Os antígenos de grupos sangüíneos $\mathrm{ABH}$ e Lewis fazem parte da composição das mucinas gástricas e têm sido implicados como receptores da bactéria na mucosa gástrica ${ }^{(4)}$.

A síntese e regulação dos antígenos de grupos sangüíneos $\mathrm{ABH}$ e Lewis envolve o produto dos genes ABH, Secretor e Lewis (Figura 1). Esta biossíntese se dá pela adição de monossacarídios feita por diferentes glicosiltransferases à cadeia precursora (glicosilação). A capacidade de secreção dos antígenos $\mathrm{ABH}$ nos fluidos corporais (saliva, sêmen, secreção vaginal, muco gástrico) está presente nos indivíduos que apresentam o gene $\boldsymbol{S e}$, sendo classificados como secretores. O tipo de antígeno secretado dependerá do genótipo do indivíduo. Os indivíduos que não apresentam este gene (sese), não expressam os antígenos $\mathrm{ABH}$ nas secreções, e quando portadores do gene Lewis secretam apenas o antígeno Le ${ }^{\mathrm{a}(8)}$.

A expressão dos antígenos ABH e Lewis varia de acordo com a origem embriológica do tecido, seu estágio de desenvolvimento e sua regulação gênica. No caso do epitélio gástrico normal de indivíduos adultos, a região superficial (ou foveolar) do tecido, está sob controle do gene Secretor, enquanto que na zona profunda ou glandular, esta expressão ocorre independente deste gene ${ }^{(23)}$.
Os fenótipos de grupos sangüíneos no indivíduo podem apresentar variações sob certas condições fisiológicas e doenças, como as neoplasias ${ }^{(10)}$. Entre essas alterações temos a expressão aumentada do antígeno Le ${ }^{\mathrm{a}}$, conseqüente do bloqueio da síntese do antígeno $\mathrm{Le}^{\mathrm{b}(29)}$. Outro exemplo é a alteração na expressão de antígenos que são sintetizados pela enzima produto do gene Secretor, levando à expressão do antígeno Le $^{\mathrm{b}}$, em não-secretores ${ }^{(25)}$.

Apesar de todas as demonstrações favoráveis à hipótese que esses antígenos influenciam a infecção e a colonização da mucosa gástrica, alguns estudos mostraram aparente perda de consistência dessa associação ${ }^{(19,28,30)}$. Desta forma, ainda existe muita controvérsia gerada, principalmente, por esses diferentes resultados, assim como pelas diferentes naturezas de cada estudo.

No presente estudo, foram analisadas as distribuições dos antígenos de grupos sangüíneas $\mathrm{ABH}$ e Lewis na mucosa gástrica com graus variáveis de gastrite crônica, associadas à presença da bactéria $H$. pylori.

\section{MATERIAL E MÉTODOS}

Analisaram-se biopsias gástricas, saliva e sangue periférico de 63 pacientes não-consecutivos, submetidos a exame endoscópico nos Hospitais Universitários Bettina de Ferro Souza e João de Barros Barreto (Universidade Federal do Pará, Belém, PA), durante o período de março a novembro de 1998. As amostras de sangue e saliva dos pacientes foram colhidas antes do exame endoscópico, para a caracterização dos fenótipos ABO, Lewis e Secretor. Previamente à coleta das amostras, foi solicitada a autorização dos pacientes para a

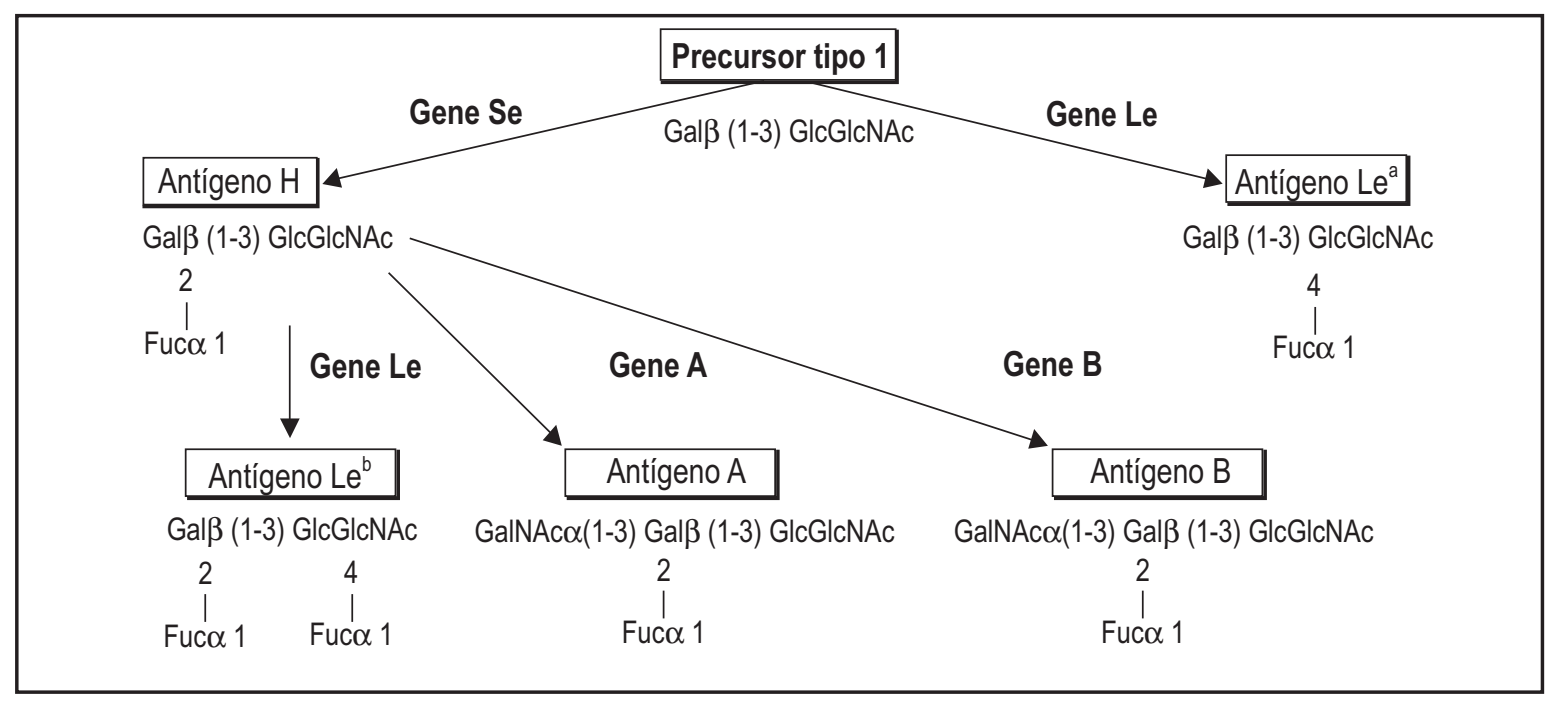

FIGURA 1- Estrutura e síntese dos antígenos ABH e Lewis, a partir do precursor tipo 1 em secretores e não-secretores. Glicosiltransferases produzidas pelos genes Secretor (Se), Lewis (Le), A e B, respectivamente: $\alpha 1,2$ fucosiltransferase; $\alpha 1,4$ fucosiltransferase; $\alpha 1,3$ $\mathrm{N}$-acetilgalactosaminiltransferase e $\alpha 1,3$ galactosiltransferase 
obtenção e utilização das amostras na pesquisa, através de termo de consentimento livre e esclarecido.

As biopsias foram fixadas em solução de formalina a $10 \%$ e encaminhadas ao Laboratório de Anatomia Patológica do Centro de Ciências da Saúde da Universidade Federal do Pará, onde foram processadas em álcool e parafinizadas. Posteriormente, foram realizados cortes histológicos seqüenciais de $5 \mu \mathrm{m}$ de espessura, dispostos em lâminas e coradas pela hematoxilina-eosina (HE) e pelo Gram modificado. As lâminas coradas pela HE foram utilizadas na análise histopatológica, enquanto que o método de coloração do Gram modificado, para a detecção do H. pylori, mediante suas características morfológicas: forma curva e espiralada, e coloração azul intensa. Todos os pacientes selecionados apresentaram diagnóstico histológico de gastrite crônica. Pacientes com outras afecções gástricas foram excluídos desta análise.

As amostras de saliva e sangue dos pacientes foram encaminhadas para o Laboratório de Imunogenética do Departamento de Genética da Universidade Federal do Pará para a caracterização dos antígenos de grupos sangüíneos. A colheita da saliva foi realizada em copo descartável, transferida para um tubo de ensaio e mantida a $4^{\circ} \mathrm{C}$. Simultaneamente foram coletados $5 \mathrm{~mL}$ de sangue periférico de cada paciente. A presença dos antígenos de grupos sangüíneos $\mathrm{ABH}$ e Lewis no sangue e na saliva dos mesmos foi determinada através da técnica dot-blot-ELISA, modificada de PFLUG et al. ${ }^{(22)}$, utilizando anticorpos monoclonais das empresas Biotest (anti-A, anti-B, antiUlex europaeus, anti-Le ${ }^{\mathrm{a}} \mathrm{e}$ anti-Le ${ }^{\mathrm{b}}$ ) como anticorpos primários $\mathrm{e}$ Sigma (anti-IgM de camundongo conjugado à fosfatase alcalina) como anticorpo secundário. As diluições dos anticorpos eram realizadas segundo as especificações dos fabricantes. O teste dot-blot-ELISA oferece alta especificidade e sensibilidade através do ensaio com anticorpos monoclonais e marcação enzimática, proporcionando reação positiva facilmente detectável pela mudança de cor visível, tornando a leitura dos resultados simples, rápida e exata, substituindo desta forma, as técnicas sorológicas convencionais.

Nas biopsias dos pacientes estudados, a expressão dos antígenos de grupos sangüíneos A, B, H, Le ${ }^{\mathrm{a}}$ e Le ${ }^{\mathrm{b}}$ foi determinada imunohisto- quimicamente, segundo a técnica da imunoperoxidase indireta ${ }^{(20,21)}$, utilizando os mesmos anticorpos primários utilizados na técnica dotblot-ELISA, e o anticorpo secundário conjugado à peroxidase (IgM Sigma).

O padrão de reação para os antígenos $\mathrm{ABH}$ e Lewis nas regiões da mucosa gástrica foi classificado segundo o tipo de coloração encontrada. Foram consideradas positivas as reações que coraram de forma homogênea toda região analisada, enquanto foram agrupadas em padrão de reação heterogênea, as que continham células com e sem coloração.

Como controle do presente estudo, foram analisadas 70 amostras de sangue de indivíduos da população da cidade de Belém, sem sintomas gástricos, para distribuição dos antígenos de grupos sangüíneos ABH e Lewis.

Foram empregados testes estatísticos adequados para a comparação, visando detectar ou não diferenças significativas entre os grupos, objeto deste estudo. O programa de computação utilizado foi o Bio Estat ${ }^{(2)}$, com os testes do qui-quadrado e teste G. A significância estatística foi definida em $95 \%(P$ valor $\leq 0.05)$.

\section{RESULTADOS}

Do total de 63 pacientes analisados nesta série, 32 eram do sexo masculino e 31 do feminino, com média de 47 anos de idade e mediana de 48 anos.

\section{Os estudos histopatológicos e as relações epidemiológicas}

As alterações histopatológicas dos pacientes da amostra estão descritos na Tabela 1 .

As associações testadas entre os resultados histopatológicos revelaram significância entre diversas variáveis. A relação entre o grau de inflamação e o grau de colonização pelo $H$. pylori, indicou inflamação mais severa em $43 \%$ (16/37) dos espécimes colonizados com maior intensidade, enquanto que $81 \%$ com inflamação leve apresentavam número reduzido de bactérias $(6 / 26)$ ou não estavam infectados $(57,69 \%)\left(\chi^{2}=8,82 ; P=0,0122\right)$.

TABELA 1 - Distribuição das características histopatológicas na amostra estudada de 63 pacientes

\begin{tabular}{|c|c|c|c|c|c|c|c|c|}
\hline \multirow{3}{*}{$\begin{array}{l}\text { Características } \\
\text { histopatológicas }\end{array}$} & \multicolumn{8}{|c|}{ Grau de intensidade } \\
\hline & \multicolumn{2}{|c|}{ Ausente } & \multicolumn{2}{|c|}{ Leve } & \multicolumn{2}{|c|}{ Moderada } & \multicolumn{2}{|c|}{ Acentuada } \\
\hline & $\mathbf{n}$ & $\%$ & n & $\%$ & n & $\%$ & n & $\%$ \\
\hline Inflamação & - & - & 26 & 41,2 & 27 & 42,9 & 10 & 15,9 \\
\hline Folículos linfóides & 18 & 28,6 & 32 & 50,8 & 13 & 20,6 & - & - \\
\hline Atividade neutrofílica & 34 & 54,0 & 26 & 41,2 & 03 & 4,8 & - & - \\
\hline Colonização pela $H$. pylori & 23 & 36,5 & 19 & 30,1 & 12 & 19,1 & 09 & 14,3 \\
\hline Metaplasia & 38 & 60,3 & 16 & 25,4 & 07 & 11,1 & 02 & 3,2 \\
\hline Displasia & 55 & 87,3 & 08 & 12,7 & - & - & - & - \\
\hline
\end{tabular}


A Tabela 2 indica que nas biopsias com graus de inflamação de moderado a intenso (inflamação forte), havia com freqüência a presença de infiltrado neutrofílico $\left(\chi^{2}=9,39 ; P=0,0022\right)$, assim como a presença de infiltrado neutrofílico é maior nos infectados pelo $H$. pylori versus não-infectados $\left(\chi^{2}=3,547 ; P=0,0596\right)$.

De acordo com a Tabela 3 , a maioria dos infectados pelo $H$. pylori tem maior ocorrência de folículos linfóides (teste-G $=8,5703 ; P=$ 0,0138), se comparada com o baixo número de folículos linfóides observados nos não-infectados. Observou-se, também, aumento da ocorrência dos folículos linfóides (teste-G $=13,5552 ; P=0,0011$ ), associado com a maior gravidade da inflamação gástrica. Existe, também, relação entre a presença da atividade neutrofílica e a maior freqüência de folículos linfóides (teste- $\mathrm{G}=6,4109 ; P=0,0405$ ).

Não foram encontradas diferenças ou associações estatisticamente significativas na relação entre as variáveis: inflamação e metaplasia, inflamação e displasia, H. pylori e metaplasia, H. pylori e displasia, metaplasia e displasia, metaplasia e atividade, metaplasia e folículo linfóide, folículo linfóide e displasia, displasia e atividade, folículo linfóide e atividade.

\section{Fenotipagem dos antígenos ABH e Lewis na saliva e nos eritrócitos}

$\mathrm{Na}$ distribuição fenotípica dos grupos sangüíneos Lewis testados (Tabela 4) observou-se discordância na expressão destes antígenos entre eritrócito e saliva, permitindo agrupar os indivíduos em: Lewis concordantes e Lewis discordantes. Os concordantes tinham antígenos Lewis idênticos no sangue e na saliva, já nos discordantes, os antígenos dos eritrócitos eram diferentes das especificidades presentes na saliva. Esta discordância representa $23,8 \%(n=15 / 63)$ do total da amostra, sendo que $17,5 \%$ (11/63) deste total pertenciam ao fenótipo eritrocitário Le(a-b-).

Quando se compara a distribuição dos subtipos dos fenótipos dos grupos sangüíneos $\mathrm{ABO}$, nota-se inversão nas frequiências (teste$\mathrm{G}=19,4210 ; P=0,0006$ ) referentes à distribuição dos subtipos $\mathrm{A}_{1} \mathrm{e}$ $\mathrm{A}_{2}$ entre a amostra de pacientes e a amostra da população em geral (Tabela 5)

\section{Perfil imunohistoquímico do epitélio gástrico na amostra de pacientes}

$\mathrm{Na}$ análise do padrão de expressão dos antígenos $\mathrm{ABH}$ na borda da mucosa de secretores, o antígeno $\mathrm{H}$ foi expresso em $77,78 \%$ dos indivíduos (49/63). Porém, em 6,35\% (4/63) esta expressão foi heterogênea. Também quanto à expressão do antígeno $\mathrm{H}$, foi encontrado um indivíduo não-secretor $(1,58 \%)$, exibindo padrão de reação heterogêneo na borda da mucosa gástrica (Figura 2)

Entre os indivíduos secretores pertencentes aos grupos sangüíneos A $(n=15 / 63 ; 23,81 \%)$ e $A B(1 / 63)$ na amostra, $12(19,04 \%)$ expressavam o antígeno A na borda da mucosa gástrica. Entre os nãosecretores, dois $(3,17 \%)$ apresentaram padrão heterogêneo de reação na borda da mucosa gástrica (Figura 2).

TABELA 2 - Relação entre presença de atividade neutrofílica e a presença de $H$. pylori e o grau de inflamação da mucosa gástrica da amostra de pacientes

\begin{tabular}{|c|c|c|c|c|c|c|c|c|}
\hline \multirow[t]{3}{*}{ Atividade neutrofílica } & \multicolumn{4}{|c|}{ Grau de inflamação } & \multicolumn{4}{|c|}{ Presença da $H$. pylori } \\
\hline & \multicolumn{2}{|c|}{ Fraco } & \multicolumn{2}{|c|}{ Forte } & \multicolumn{2}{|c|}{ Ausente } & \multicolumn{2}{|c|}{ Presente } \\
\hline & $\mathbf{n}$ & $\%$ & $\mathbf{n}$ & $\%$ & $\mathbf{n}$ & $\%$ & $\mathbf{n}$ & $\%$ \\
\hline Ausente & 20 & 31,8 & 14 & 22,2 & 16 & 25,4 & 18 & 28,6 \\
\hline Presente & 06 & 9,5 & 23 & 36,5 & 07 & 11,1 & 22 & 34,9 \\
\hline Total & 26 & 41,3 & 37 & 58,7 & 23 & 36,5 & 40 & 63,5 \\
\hline
\end{tabular}

TABELA 3 - Relação entre o grau de ocorrência de folículos linfóides na mucosa gástrica e a presença de $H$. pylori, o grau de inflamação e a presença de atividade neutrofílica na amostra de pacientes

\begin{tabular}{|c|c|c|c|c|c|c|c|c|c|c|c|c|}
\hline \multirow{3}{*}{$\begin{array}{l}\text { Grau de folículo } \\
\text { linfóide }\end{array}$} & \multicolumn{4}{|c|}{ Presença da $H$. pylori } & \multicolumn{4}{|c|}{ Grau de inflamação } & \multicolumn{4}{|c|}{ Atividade neutrofílica } \\
\hline & \multicolumn{2}{|c|}{ Ausente } & \multicolumn{2}{|c|}{ Presente } & \multicolumn{2}{|c|}{ Fraco } & \multicolumn{2}{|c|}{ Forte } & \multicolumn{2}{|c|}{ Fraco } & \multicolumn{2}{|c|}{ Forte } \\
\hline & n & $\%$ & $\mathbf{n}$ & $\%$ & $\bar{n}$ & $\%$ & $\bar{n}$ & $\%$ & $\mathbf{n}$ & $\%$ & $\mathbf{n}$ & $\%$ \\
\hline Ausente & 10 & 15,8 & 08 & 12,7 & 07 & 11,1 & 11 & 17,5 & 08 & 12,7 & 10 & 15,9 \\
\hline Leve & 12 & 19,1 & 20 & 31,7 & 19 & 30,2 & 13 & 20,6 & 22 & 34,9 & 10 & 15,9 \\
\hline Moderado & 01 & 1,6 & 12 & 19,1 & - & - & 13 & 20,6 & 04 & 6,3 & 09 & 14,3 \\
\hline Total & 23 & 36,5 & 40 & 63,5 & 26 & 41,3 & 37 & 58,7 & 34 & 53,9 & 29 & 46,1 \\
\hline
\end{tabular}


TABELA 4 - Distribuição dos fenótipos de grupos sangüíneos ABO, estado secretor de ABH e os fenótipos Lewis eritrocitário e salivar na amostra de pacientes

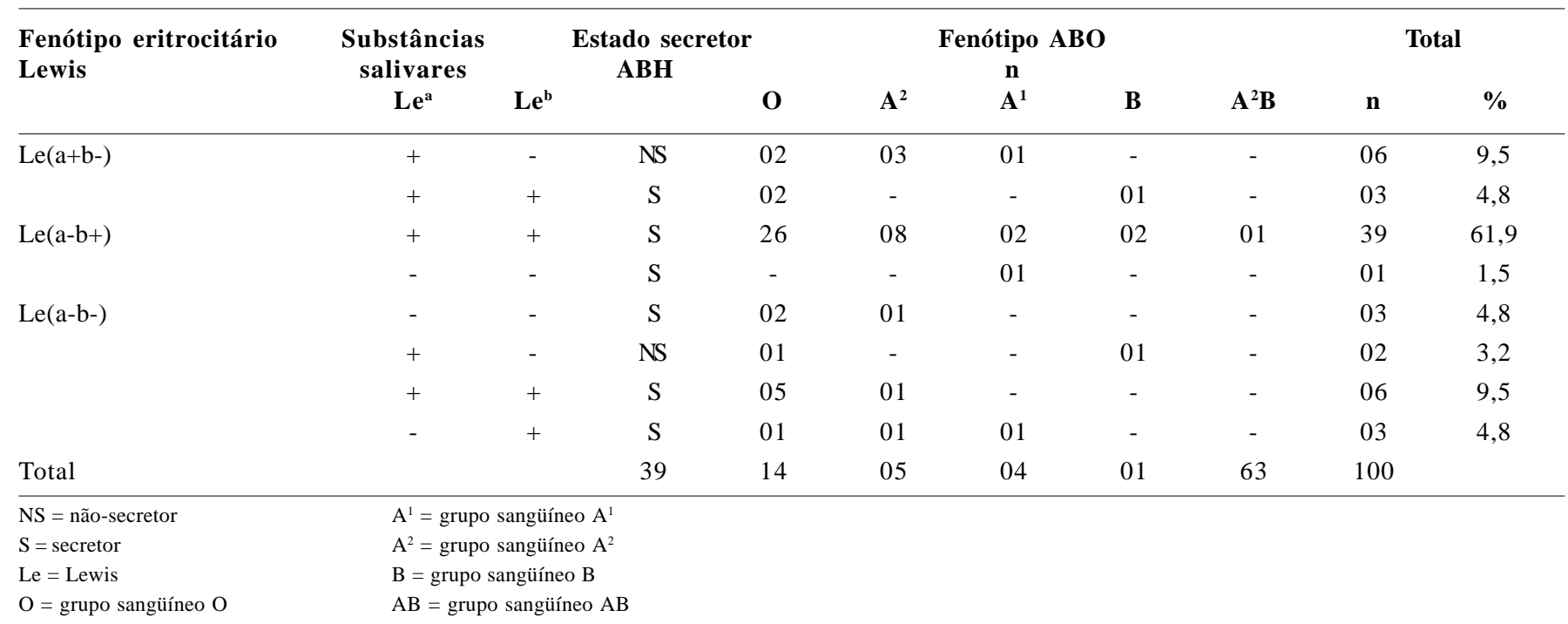

TABELA 5 - Distribuição dos grupos sanguíneos eritrocitários ABH na amostra de pacientes e na amostra da população da cidade de Belém, PA

\begin{tabular}{lcccc}
\hline \multirow{2}{*}{ Fenótipo eritrocitário ABH } & \multicolumn{2}{c}{ Amostra de pacientes } & \multicolumn{2}{c}{ Amostra da população } \\
\cline { 2 - 5 } & $\mathrm{n}$ & $\%$ & $\mathrm{n}$ & $\%$ \\
\hline $\mathrm{O}$ & 39 & 61,9 & 40 & 57,1 \\
$\mathrm{~A}^{1}$ & 05 & 8,0 & 20 & 28,6 \\
$\mathrm{~A}^{2}$ & 14 & 22,2 & 02 & 2,9 \\
$\mathrm{~B}$ & 04 & 6,3 & 05 & 7,1 \\
$\mathrm{AB}$ & 01 & 1,6 & 03 & 4,3 \\
Total & 63 & 100 & 70 & 100 \\
\hline
\end{tabular}

Nos secretores pertencentes ao grupo sangüíneo $B(n=4 ; 6,34 \%)$ e $\mathrm{AB}(1 / 63)$, a expressão do antígeno B na borda da mucosa gástrica foi observada em $100 \%$ dos indivíduos. Um indivíduo não-secretor $(1,58 \%)$ apresentou padrão de reação negativo para o antígeno B na borda da mucosa (Figura 2).

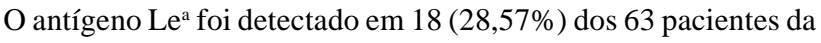
amostra. Em 10 pacientes $(15,87 \%)$ secretores houve expressão deste antígeno na borda da mucosa gástrica. Deste total, três $(4,76 \%)$ apresentavam padrão heterogêneo. Todos os oito indivíduos nãosecretores $(100 \%)$ apresentaram a expressão deste antígeno na região foveolar da mucosa gástrica, assim como, expressaram também o antígeno Le ${ }^{\mathrm{b}}$ na borda da mucosa, sendo que em um (12,5\%) indivíduo o padrão da reação foi heterogêneo. $\mathrm{O}$ antígeno $\mathrm{Le}^{\mathrm{b}}$ foi detectado na superfície da mucosa de 52 dos 55 secretores $(94,54 \%)$ da amostra, sendo que $5(9,61 \%)$ dos 52 tinham expressão heterogênea (Figura 3).

Nos pacientes com metaplasia intestinal na mucosa gástrica, foi verificada a expressão dos antígenos $\mathrm{ABH}, \mathrm{Le}^{\mathrm{a}}$ e $\mathrm{Le}^{\mathrm{b}}$ em áreas de tecido normal e áreas com metaplasia. Notou-se que o perfil imunohistoquímico diferiu marcadamente entre o epitélio gástrico e as glândulas metaplásicas na expressão dos antígenos $\mathrm{H} \mathrm{e} \mathrm{Le}$ (Figuras 4 e 5). Observou-se perda de reatividade para o antígeno $\mathrm{H}$ nas áreas onde há metaplasia, enquanto que para o antígeno Le ${ }^{a}$ houve ganho de expressão. 


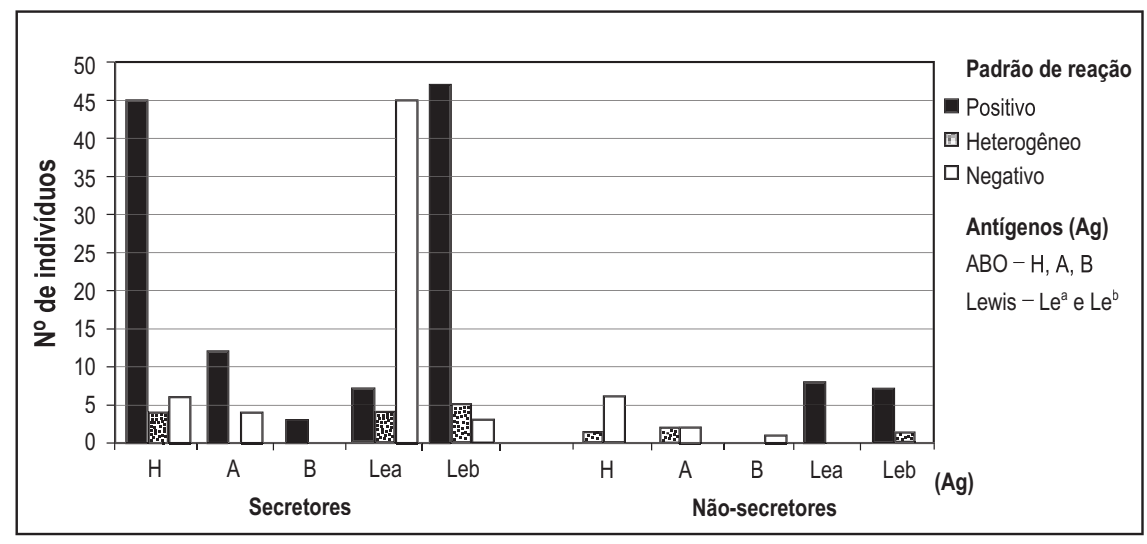

FIGURA 2 - Expressão dos antígenos ABH e Lewis na borda da mucosa gástrica dos indivíduos secretores e não-secretores da amostra

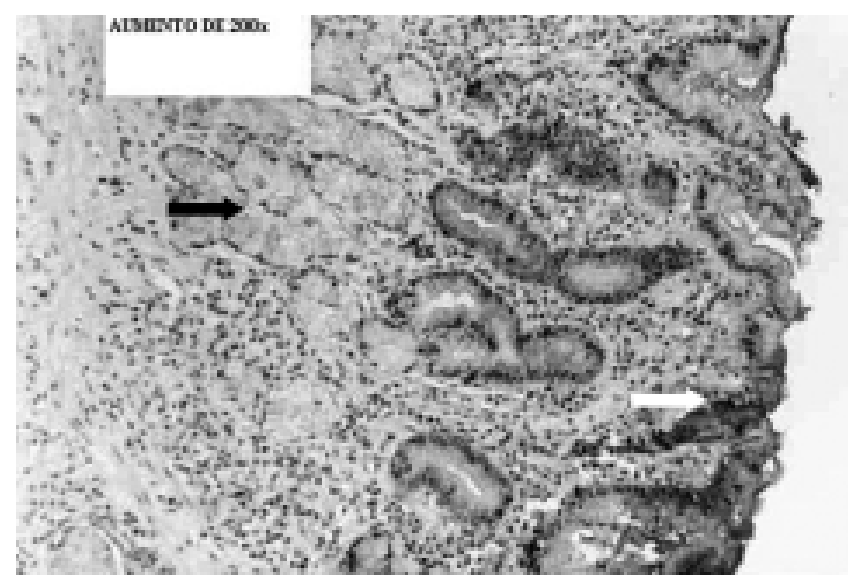

FIGURA 3 - Padrão de expressão Le ${ }^{b}$ na mucosa gástrica com positividade homogênea (seta branca) nas regiões da borda e de transição, e heterogênea (seta preta) na região do fundo. Coloração de fundo Hematoxilina.

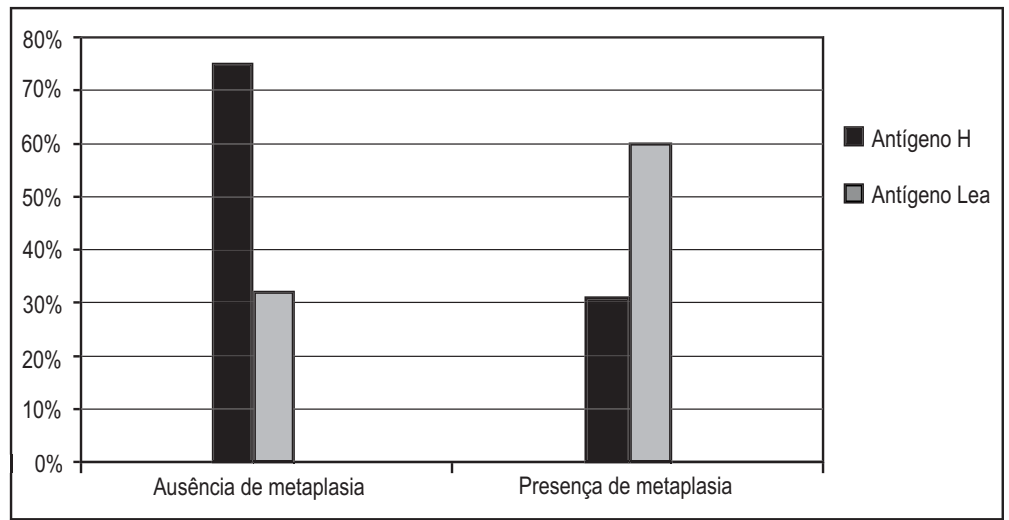

FIGURA 4 - Reatividade para os antígenos $\mathrm{H}$ e Le em áreas de ausência e presença de metaplasia intestinal na mucosa gástrica dos pacientes 


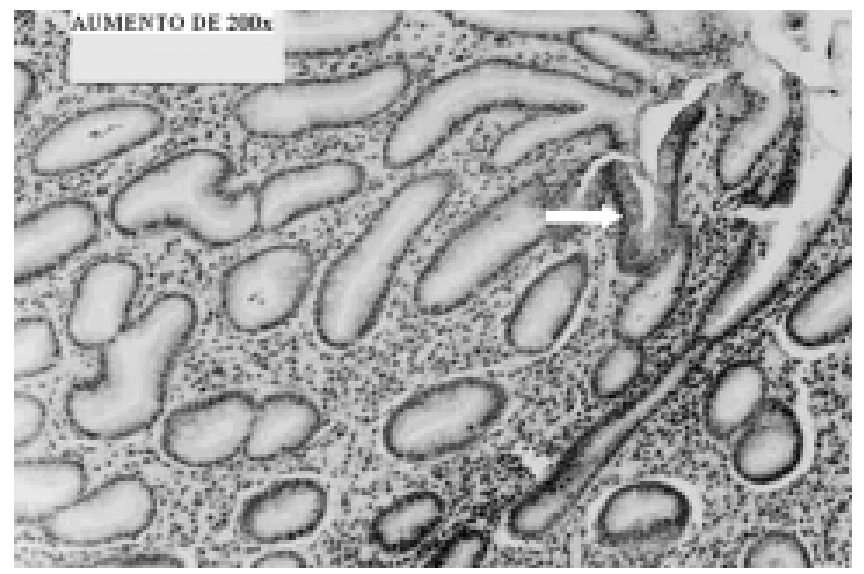

FIGURA 5 - Expressão do antígeno Le (seta) em áreas com metaplasia intestinal na mucosa gástrica pelo método da imunoperoxidase indireta. Coloração de fundo Hematoxilina.

\section{Distribuição dos grupos sangüíneos ABH e Lewis na amostra de pacientes e sua relação com a infecção pela $H$. pylori}

Quanto à prevalência do $H$. pylori, entre os grupos sangüíneos $\mathrm{ABO}$, Lewis e Secretor, não foram encontradas diferenças significativas entre indivíduos de diferentes grupos sangüíneos na amostra de pacientes infectados versus não-infectados pelo $H$. pylori (Tabelas 6, 7 e 8).
Interrelações dos fenótipos de grupos sangüíneos salivar e eritrocitário com a distribuição dos antígenos na superfície da mucosa gástrica

Levando-se em consideração os dados histopatológicos dos pacientes com fenótipos Lewis discordantes (15/63), 7/63 (11,11\%)

TABELA 6 - Prevalência dos grupos sangüíneos ABO entre pacientes infectados e não infectados pelo $H$. pylori

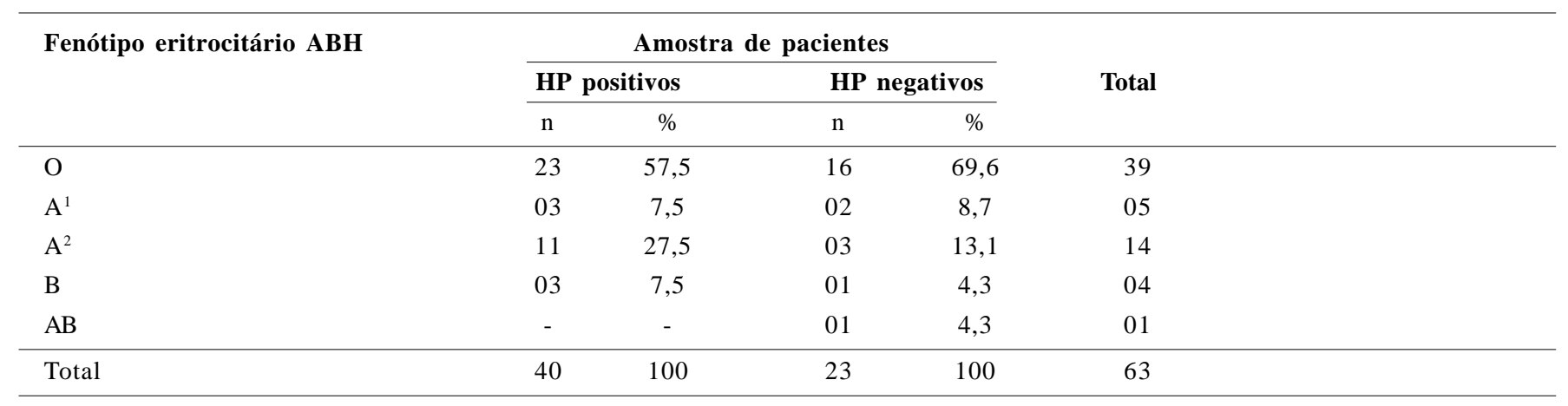

(Teste- $\mathrm{G}=2.3298 ; P=0.6754)$

TABELA 7 - Prevalência dos grupos sangüíneos Lewis entre pacientes infectados e não infectados pelo $H$. pylori

\begin{tabular}{|c|c|c|c|c|c|}
\hline \multirow[t]{2}{*}{ Fenótipo eritrocitário Lewis } & \multicolumn{4}{|c|}{ Amostra de pacientes } & \multirow{2}{*}{ Total } \\
\hline & $\mathrm{n}$ & $\%$ & $\mathrm{n}$ & $\%$ & \\
\hline $\operatorname{Le}(a+b-)$ & 07 & 17,5 & 02 & 8,7 & 09 \\
\hline $\operatorname{Le}(a-b+)$ & 23 & 57,5 & 17 & 73,9 & 40 \\
\hline
\end{tabular}

(Teste-G $=1.7639 ; P=0.4140)$ 
Aguiar DCF, Corvelo TCO, Araújo M, Cruz EM, Daibes S, Assumpção MB. Expressão dos antígenos ABH e Lewis na gastrite crônica e alterações pré-neoplásicas da mucosa gástrica

TABELA 8 - Estado Secretor dos antígenos ABH entre pacientes infectados e não infectados pelo H. pylori

\begin{tabular}{lccccc}
\hline \multirow{2}{*}{ Estado Secretor de ABH } & \multicolumn{3}{c}{ Amostra de pacientes } & \multirow{2}{*}{ Total } \\
\cline { 2 - 5 } & HP positivos & \multicolumn{2}{c}{ HP negativos } & & \\
\cline { 2 - 5 } & $\mathrm{n}$ & $\%$ & $\mathrm{n}$ & $\%$ & \\
\hline Secretor & 35 & 87,5 & 20 & 86,9 & 55 \\
Não-secretor & 5 & 12,5 & 3 & 13,1 & 08 \\
Total & 40 & 100 & 23 & 100 & 63 \\
\hline
\end{tabular}

(Teste- $\mathrm{G}=0.1115 ; P=0.7385$ )

estavam infectados pelo $H$. pylori, $2 / 63(3,17 \%)$ apresentavam alterações pré-malignas no tecido gástrico, $4 / 63(6,35 \%)$ apresentavam tanto a infecção pelo $H$. pylori, quanto alterações pré-malignas no epitélio gástrico e somente 2/63 (3,17\%) não estavam infectados pela bactéria nem apresentavam alterações pré-malignas no tecido. Constatou-se ainda que entre 60\% (9/15) dos pacientes agrupados como Lewis discordantes e do fenótipo eritrocitário Le(a-b-) e que na saliva secretavam as substâncias $\mathrm{ABH}$ e Le ${ }^{\mathrm{b}}$, a reatividade para estes antígenos no epitélio gástrico concorda com o fenótipo salivar.

Nos pacientes Lewis concordantes (48/63; 76,19\%), 33 (52,38\%) indivíduos apresentaram distribuição anormal dos antígenos $\mathrm{ABH}$ e Lewis na borda da mucosa gástrica, sendo que 9/63 (14,29\%) pacientes estavam infectados com o $H$. pylori, $10(15,87 \%)$ biopsias apresentavam alterações pré-malignas no tecido gástrico, 13/63 apresentavam concomitantemente a infecção pela bactéria e alterações pré-neoplásicas na mucosa gástrica e apenas em 1/63 (1,59\%) não foi detectada a presença da bactéria ou alterações como a metaplasia e a displasia no tecido gástrico.

\section{DISCUSSÃO}

Nos últimos anos, muitos mecanismos têm sido propostos para explicar o sucesso da bactéria $H$. pylori em colonizar um ambiente hostil como o estômago humano ${ }^{(15)}$. Porém, a presença da bactéria não constitui fator exclusivo no desenvolvimento dessas patologias. Fatores ambientais e a predisposição genética do indivíduo também contribuem para o aparecimento desses tipos de achados ${ }^{(26)}$. Neste estudo, a taxa de infecção pela bactéria encontrada está de acordo com valores esperados para a população de Belém, $\mathrm{PA}^{(18,24)}$ e Brasil $^{(6)}$. Porém, é bem provável que os valores de positividade nesta amostra estivessem aumentados se métodos diagnósticos mais sensíveis fossem utilizados, como por exemplo, a sorologia para anticorpos contra o $H$. pylori, isso porque a sensibilidade do exame histopatológico depende da distribuição da bactéria na mucosa gástrica, que se dá de forma focal ou segmentada. Esta diferença de positividade devido à sensibilidade do método foi demonstrada recentemente por AZEVEDO e BARROS ${ }^{(3)}$, em um grupo de pacientes com gastrite crônica, em que o índice de positividade para a bactéria na análise histopatológica foi de $68 \%$, enquanto que pelo exame sorológico, foi superior a $90 \%$. Outro fator relevante é que entre os pacientes diagnosticados como $H$. pylori negativos, 15,87\% (10/63) apresentavam metaplasia intestinal. Na metaplasia é incomum a presença da bactéria, pois este tipo de epitélio não favorece seu crescimento ${ }^{(31)}$.

Atualmente, existem evidências de que o grau de gravidade da gastrite está relacionado ao grau de colonização da mucosa gástrica pelo H. pylori ${ }^{(34)}$, em concordância com o que foi encontrado neste estudo. A relação encontrada entre a atividade neutrofílica e o grau de inflamação é, possivelmente, consequiência da infecção pelo H. pylori ${ }^{(14)}$. A intensidade do infiltrado neutrofílico variou entre indivíduos e está, possivelmente, relacionada com o dano inflamatório da mucosa e, provavelmente, com o tipo de cepa da bactéria presente ${ }^{(31)}$ e não com o grau de colonização na mucosa. O H. pylori produz substâncias quimiotáticas que atraem e ativam neutrófilos e outras células inflamatórias que, através de estímulo intermitente, geram a agressão dos tecidos do hospedeiro ${ }^{(34)}$.

A mucosa gástrica normal não apresenta folículos linfóides, normalmente encontrados na mucosa do cólon e do intestino delgado. A presença de folículos linfóides neste estudo está relacionada ao grau de inflamação da mucosa, à presença do $H$. pylori e à atividade neutrofílica. Estas correlações já descritas previamente, sugerem que a proliferação linfocítica está relacionada à resposta imune do hospedeiro pela presença do H. pylori ${ }^{(27)}$.

Observou-se discordância entre os fenótipos eritrocitário e salivar dos antígenos Lewis nos pacientes. Os antígenos Lewis são produzidos a partir de células epiteliais exócrinas que liberam estes antígenos no plasma, do qual são adsorvidos às hemácias. Desta forma, a expressão desses antígenos ao nível eritrocitário pode não refletir o verdadeiro fenótipo Lewis. Algumas condições fisiológicas e de doenças, podem tornar o indivíduo incapaz de sintetizar os antígenos em quantidades detectáveis sorologicamente nas hemácias, porém o fenótipo Lewis salivar permanece inalterado. Assim, foi detectada a presença de $\mathrm{Le}^{\mathrm{a}} \mathrm{e}$ $\mathrm{Le}^{\mathrm{b}}$ na saliva e/ou nas células gástricas de todos os pacientes fenotipicamente positivos, independentemente da expressão dos antígenos Lewis nos eritrócitos. Nesses casos, onde existe a discordância eritrócito-saliva, o fenótipo expresso no epitélio foveolar dos pacientes, concorda, na sua maioria, com o fenótipo salivar ${ }^{(10)}$. 
Existem na literatura poucos estudos epidemiológicos de predisposição genética para doenças gástricas. Entretanto, estudos prévios mostraram associação dos antígenos de grupos sanguiíneos Lewis e $\mathrm{ABH}$ com a susceptibilidade à colonização pelo $H$. pylori. ALKOUT et al. ${ }^{(1)}$ evidenciaram que o aumento da susceptibilidade dos indivíduos do grupo $\mathrm{O}$ para infecção pelo H. pylori, poderia ser parcialmente causado por densidade elevada de colonização por esta bactéria comparada aos outros grupos sangüíneos. ILVER et al. ${ }^{(12)}$ indicaram que existe maior susceptibilidade entre os indivíduos dos grupos sangüíneos $\mathrm{O}$ e Le $\mathrm{Le}^{\mathrm{b}}$ à infecção pelo $H$. pylori, por estes apresentarem maior quantidade de antígenos fucosilados, já que o receptor da bactéria à superfície gástrica contém fucose ${ }^{(4)}$.

Quando a prevalência do $H$. pylori foi analisada na presente série e comparada à amostra da população da cidade de Belém, considerando os fenótipos de grupos sangüíneos $\mathrm{ABO}$, Lewis e estado Secretor de $\mathrm{ABH}$, não foi encontrada nenhuma diferença significativa, a exemplo do que tem sido descrito em estudos prévios ${ }^{(30,33)}$. Porém, resultado interessante a ser destacado é a associação com os subgrupos do tipo sangüíneo A. Observou-se que no grupo de pacientes houve o predomínio do subgrupo $\mathrm{A}_{2}$, enquanto que, na amostra da população em geral, a frequiência de $\mathrm{A}_{1}$ é muito mais elevada do que $\mathrm{A}_{2}$. A diferença entre estas variantes antigênicas se dá pelo fato da transferase $A_{1}$ ser mais eficiente que a transferase $A_{2}$ na conversão do antígeno $H$, para a formação do determinante $\mathrm{A}^{(13)}$. Dessa forma, a principal diferença entre os dois subgrupos de A é que a quantidade de substância H convertida em antígeno A é maior no subgrupo $A_{1}$. Isto pode justificar parcialmente o aumento da frequiência do subgrupo $A_{2}$ na amostra de pacientes, já que este fenótipo $\mathrm{A}_{2}$ tem maior quantidade de substância $\mathrm{H}$, e portanto, maior disponibilidade de antígenos fucosilados. É importante ressaltar que se desconhece entre os estudos realizados com a associação dos grupos sangüíneos e a infecção pelo $H$. pylori, que em algum deles tenha sido investigada a freqüência dos subgrupos de A entre as doenças gástricas.

Nos dados analisados para o epitélio foveolar de indivíduos secretores, constatou-se que a expressão dos antígenos $\mathrm{ABH}$ e $\mathrm{Le}^{\mathrm{b}}$ totalizou mais de $80 \%$ da amostra e que o perfil de expressão destes antígenos, nos casos de gastrite crônica com ausência de alterações pré-malignas, não mostrou diferença em relação ao padrão clássico de expressão na mucosa gástrica. Por outro lado, na maioria dos pacientes onde ocorreu reação negativa ou havia reação positiva, mas com padrão de expressão heterogêneo para estes antígenos, foi constatada comumente a presença de metaplasia intestinal e/ou de infecção pelo H. pylori. Este achado demonstra que o padrão de glicosilação parece sofrer alterações gradativas e progressivas ocasionadas pela infecção bacteriana que, conseqüentemente, influencia no padrão de diferenciação e regulação tecidual ${ }^{(5)}$.

Em alguns indivíduos secretores da amostra de pacientes, houve também a co-expressão dos antígenos $\mathrm{Le}^{\mathrm{a}} \mathrm{e} \mathrm{Le}^{\mathrm{b}}$ no epitélio foveolar da mucosa. Dados publicados por ERNST et al. ${ }^{(9)}$ citam que a ocorrência da síntese e co-expressão destes antígenos Lewis no epitélio foveolar de secretores é compatível com a síntese e distribuição normal destes antígenos. Desta forma, SAKAMOTO et al. ${ }^{(25)}$ dividem os indivíduos secretores em dois grupos, segundo a expressão do antígeno Le ${ }^{a}$ no epitélio foveolar da mucosa gástrica: um grupo expressando o antígeno $\mathrm{Le}^{\mathrm{a}}$ juntamente com o antígeno Le $\mathrm{e}^{\mathrm{b}}$, e outro onde não há expressão de $L^{a} e^{a}$ em nenhuma região do epitélio. Explicação encontrada para esta variação é que, em heterozigotos para o gene Secretor, haja atividade diminuída das $\alpha$-1, 2-fucosiltransferases na mucosa de secretores, viabilizando, assim, a produção do antígeno $\mathrm{Le}^{\mathrm{a}}$.

Foi observada a perda de expressão do antígeno A na mucosa de quatro pacientes secretores da amostra. Em dois deles havia metaplasia e nos outros dois havia processo inflamatório acentuado da mucosa gástrica. Por outro lado, nos pacientes não-secretores, foi observada expressão normal do antígeno Le ${ }^{\mathrm{a}}$, além da expressão freqüentemente incompatível do antígeno Le $\mathrm{e}^{\mathrm{b}}$. Esta expressão residual do antígeno $\mathrm{Le}^{\mathrm{b}}$ no epitélio foveolar de pacientes não-secretores poderia ser devido a outra $\alpha$-2-fucosiltransferase, provavelmente pela enzima $\mathrm{H}$. De acordo com MURATA et al. ${ }^{(17)}$, a presença da inflamação poderia mudar o padrão de expressão relativo aos antígenos de cadeias tipo 1 e 2, descritas para tecidos normais.

As modificações no padrão de expressão dos antígenos do tipo carboidratos podem estar correlacionadas com o prognóstico de doenças malignas $^{(7)}$. As mais encontradas envolvem o desaparecimento ou perda de certos antígenos, seguidos pela neo-expressão de outros, gerando expressão de antígenos incompatível com o genótipo do indivíduo $^{(25)}$. Tem sido verificado ${ }^{(11)}$ que determinados casos de metaplasia intestinal exibem secreção alterada de mucinas. Neste sentido, a expressão inapropriada dos antígenos Lewis foi descrita por TORRADO et al. ${ }^{(29)}$, onde indivíduos do fenótipo Le(a-b+) desenvolvem bloqueio na síntese do antígeno $\mathrm{Le}^{\mathrm{b}}$, resultando no acúmulo dos precursores e formação intensificada do antígeno $\mathrm{Le}^{\mathrm{a}}$. Os resultados do presente estudo também indicam expressão acentuada do antígeno $\mathrm{Le}^{\mathrm{a}} \mathrm{em}$ áreas com metaplasia intestinal na mucosa de secretores. Esta expressão inapropriada do antígeno Le ${ }^{a}$ ocorreu em $76 \%$ dos casos com lesões pré-malignas e somente em $29 \%$ com gastrite crônica. E ainda, neste grupo sem lesões pré-malignas e que expressavam $\mathrm{Le}^{\mathrm{a}}, 18 \%$ dos pacientes estavam infectados pelo $H$. pylori. Tais evidências sugerem que a progressiva expressão do antígeno Le sofre influência na evolução do processo cancerígeno.

Ao contrário do antígeno $\mathrm{Le}^{\mathrm{a}}$, o antígeno $\mathrm{H}$ revelou expressão decrescente nas áreas de metaplasia intestinal. Isto deve ocorrer pela diminuição da atividade do gene Secretor, determinando que grande parte do precursor seja transformado em antígeno Le ${ }^{\mathrm{a}}$, pela enzima do gene Lewis, diminuindo, assim, a expressão do antígeno $\mathrm{H}$ e Le $\mathrm{Le}^{\mathrm{b}}$ nestes tecidos e, conseqüentemente, provocando as freqüentes deleções de antígenos A e/ou B, proporcionando a atividade aumentada da enzima Lewis e neo-expressão de $\mathrm{Le}^{\mathrm{a}}$. Tal relação é de interesse, porque 
padrões anômalos de expressão de antígenos do tipo carboidratos podem estar associados com o aumento do risco relativo de transformação maligna e/ou de elevado potencial metastático. Estes achados sugerem função importante de verificação da expressão da $\mathrm{Le}^{\mathrm{a}}$, como marcador associado a mudanças no padrão de proliferação e diferenciação celular e, também, de alteração da expressão dos antígenos de grupo sangüíneo na superfície celular, podendo auxiliar decisivamente no diagnóstico e prognóstico de diversas afecções gástricas. Estudos adicionais são necessários para melhor elucidar mecanismos genéticos e interações gene-ambiente no processo multifatorial da carcinogênese gástrica.

\section{CONCLUSÕES}

A taxa de infecção pelo $H$. pylori detectada na amostra de pacientes é compatível com as taxas de prevalência descritas para a população da cidade de Belém e outras regiões de países em desenvolvimento. A prevalência da infecção pelo $H$. pylori não mostrou associação significativa com os fenótipos $\mathrm{ABO}$, Lewis e Secretor, entretanto a freqüência aumentada de antígenos fucosilados $\left(\mathrm{O}, \mathrm{A}_{2}\right.$ e $\left.\mathrm{Le}^{\mathrm{b}}\right)$ são indicadores de predisposição genética dos portadores destes fenótipos de grupo sangüíneo para as doenças gástricas.
No grupo de pacientes, as freqüências dos subgrupos de $\mathrm{A}\left(\mathrm{A}_{1} \mathrm{e}\right.$ $\mathrm{A}_{2}$ ) apresentavam diferenças significativas quando comparadas com as frequiências da amostra da população de Belém.

O perfil de expressão dos antígenos $\mathrm{ABH}$ e $\mathrm{Le}^{\mathrm{b}}$ no epitélio foveolar de pacientes secretores, com gastrite crônica, porém sem lesões prémalignas, não diferiu significativamente, em relação ao padrão clássico de expressão da mucosa gástrica.

Nas áreas do epitélio com metaplasia intestinal, foi observada perda de expressão dos antígenos $\mathrm{H}$ e Le , provável conseqüência da inibição da atividade enzimática, com acúmulo do precursor de cadeia tipo 1, reduzindo a expressão de antígenos $\mathrm{ABH}$ e Le $\mathrm{Le}^{\mathrm{b}}$. Ainda, a expressão acentuada de $\mathrm{Le}^{\mathrm{a}} \mathrm{em}$ pacientes secretores e, particularmente, em áreas com metaplasia, indica que a progressiva expressão deste antígeno sofre influência na evolução para transformação maligna.

Em pacientes não-secretores, foi observada a expressão normal do antígeno Le $\mathrm{e}^{\mathrm{a}}$, além da expressão freqüentemente incompatível do antígeno Le $\mathrm{L}^{\mathrm{b}}$ o que pode ser devido a outra a-2-fucosiltransferase, possivelmente pela enzima $\mathrm{H}$.

Os antígenos de grupos sangüíneos investigados refletem padrões diferentes de diferenciação celular, constituindo-se em potenciais marcadores, utilizáveis no diagnóstico e prognóstico de diversas doenças gástricas.

Aguiar DCF, Corvelo TCO, Araújo M, Cruz EM, Daibes S, Assumpção MB. Expression of ABH and Lewis antigens in chronic gastritis and preneoplasic alterations in gastric mucosa. Arq Gastroenterol 2002;39(4):222-232.

ABSTRACT - Background - The major cause for chronic gastritis in human is the infection by the Helicobacter pylori. The blood group antigens present at the gastric mucous are described as possible receptor for this bacteria in the epithelium. The alterations in the expression of blood group patterns are associated with the development of gastric cancer. Objectives - Verify the H. pylori prevalence and examine the immunohistochemical distribution of the $\mathrm{ABH}$ and Lewis antigens expression to correlate with histopathological alterations. Patients and Methods - From 63 chronic gastritis patients were investigated gastric biopsies, blood and saliva samples by dot-blot-ELISA, indirect immunoperoxidase and hematoxylin-eosin and Gram. Results - No significant association between the presence of the bacteria and the ABH, Lewis and Secretor phenotype was found. For the majority of the patients the antigen expression of the ABH and Lewis blood group was restricted mainly to the foveola epithelium of the gastric mucosa, similar to the saliva. The inappropriate expression of these antigens occurred always in the presence of $\mathrm{H}$. pylori and/or preneoplastic alterations of the gastric mucosa. In areas with intestinal metaplasias we also observed reduced reactivity for the $\mathrm{H}$ and $\mathrm{Le}^{\mathrm{b}}$ antigens and mainly the induced expression of Le $\mathrm{e}^{\mathrm{a}}$. Conclusion - Alterations in the pattern of the glycosylation of this antigens are interesting, because they reflect different stages in the cellular differentiation and become potential markers in the diagnostic evaluation and prognosis of gastric pathologies.

HEADINGS - Helicobacter pylori. Helicobacter infections. Gastritis. Blood groups. 


\section{REFERÊNCIAS BIBLIOGRÁFICAS}

1. Alkout AM, Blackwell CC, Weir DM, Poxton IR, Elton RA, Luman W, Palmer K. Isolation of a cell surface component of Helicobacter pylori that binds $\mathrm{H}$ type 2 , Lewis $^{\mathrm{a}}$, and Lewis ${ }^{\mathrm{b}}$ antigens. Gastroenterology 1997;112:1179-87.

2. Ayres M, Ayres Jr M, Ayres DL, Santos AS. Programa BioEstat 2.0 - Aplicações estatísticas nas áreas das ciências biológicas e médicas. Brasília: Sociedade Civil Mamirauá MCT - CNPq; 2000.

3. Azevedo RSN, Barros GGG. Avaliação dos métodos de diagnóstico histológico e sorológico voltados à infecção pela Helicobacter pylori em gastrites crônicas [trabalho de conclusão do curso de medicina]. Belém, Pará: Universidade Federal do Pará; 2001.

4. Borén T, Falk P, Roth KA, Larson G, Normark S. Attachment of Helicobacter pylori to human gastric epithelium mediated by blood group antigens. Science 1993;262:1892-5

5. Byrd JC, Yan P, Sterberg L, Yunker CK, Scheiman JM, Bresalier RS. Aberrant expression of gland-type gastric mucin in surface epithelium of Helicobacter pylori-infected patients. Gastroenterology 1997;113:455-64

6. Coelho LGV, Das SS, Karim QN, Walker MM, Queiroz DMM, Mendes EN, Lima JR GF, Oliveira CA, Baron JH, Castro LP. Campylobacter pyloridis in the upper gastrointestinal tract: a Brazilian study. Arq Gastroenterol 1987;24:5-9.

7. Dabelsteen E. Cell surface carbohydrates as prognostic markers in human carcinomas. J Pathol 1996;179:358-69.

8. D'Adamo PJ, Kelly GS. Metabolic and immunologic consequences of $\mathrm{ABH}$ secretor and Lewis subtype status. Altern Med Rev 2001 6:390-405.

9. Ernst C, Atkinson B, Wysocka M. Monoclonal antibody localization of Lewis antigens in fixed tissues. Lab Invest 1984;50:394-400.

10. Henry S, Oriol R, Samuelsson B. Lewis histo-blood group system and associated secretory phenotypes. Vox Sang 1995;69:166-82.

11. Huang CB, Xu J, Huang JF, Meng XY. Sulphomucin colonic type intestinal metaplasia and carcinoma of the stomach. Cancer 1986;57:1370-5.

12. Ilver D, Arnqvist A, Ögren J, Frick I-M, Kersulyte D, Incecik ET, Berg DE, Covacci A, Engstrand L, Borén T. Helicobacter pylori adhesin fucosilated histo-blood group antigens revelead by retagging. Science 1998;279:373-7.

13. King MJ. Blood grups antigens on humam erythrocytes-distribution, structure and possible functions. Biochim Biophys Acta 1994;1197:15-44

14. Marshall BJ, Warren JR. Unidentified curved Bacilli in the stomach of patients with gastritis and peptic ulceration. Lancet 1984;1:1311-4.

15. Marshal BJ. Helicobacter pylori. Am J Gastroenterol 1994;89 Suppl 8:S116-28.

16. Megraud F. Epidemiology of Helicobacter pylori infection: where are we in 1995? Eur J Gastroenterol Hepatol 1995;7:292-5.

17. Murata K, Egami H, Shibata Y, Sakamoto K, Misumi A, Ogawa M. Expression of blood group-related antigens, ABH, Lewis ${ }^{\mathrm{a}}$, Lewis ${ }^{\mathrm{b}}$, Lewis ${ }^{\mathrm{x}}$, Lewis ${ }^{\mathrm{y}}$, CA19-9, and CSLEX1 in early cancer, intestinal metaplasia, and univolved mucosa of the stomach. Am J Clin Pathol 1992;98:67-75.

18. Neto AS. Detecção do Campylobacter pylori através do gastroteste: análise de 50 pacientes [trabalho de conclusão do curso de medicina]. Belém, Pará: Universidade Federal do Pará; 1990.
19. Oberhuber G, Kranz A, Dejaco C, Dragosics B, Mosberger I, Mayr W, Radaszkiewicz T. Blood groups Lewis sup b and $\mathrm{ABH}$ expression in gastric mucosa: lack of inter-relation with Helicobacter pylori colonisation and occurrence of gastric MALT lymphoma. Gut 1997;41:37-42.

20. Pedal I. Blutgruppen-Immunhistochemie. Stuttgart: Georg Thieme Verlag; 1987.

21. Pedal I, Reichert W, Oliveira-Corvelo TC. Das Samenbläschenepithel Lewispositiver Individuen sezerniert $\mathrm{Le}^{\mathrm{a}}$ in sialyerter Form. Beitr Gerichtl Med 1989;47:153-8.

22. Pflug W, Bässler G, Eberspacher B. ABO and Lewis typing of secretion stains on nitrocellulose membranes using a new dot-blot-ELISA technique. Forensic Sci Int 1989;43:171-82.

23. Ravn V, Dabelsteen E. Tissue distribution of histo-blood group antigens. APMIS 2000;108:1-28.

24. Sagica FES. 2000. Perfil imunohistoquímico da mucosa gástrica no desenvolvimento do câncer gástrico [dissertação]. Belém, Pará: Universidade Federal do Pará / Museu Paraense Emílio Goeldi / EMBRAPA; 2000.

25. Sakamoto S, Watanabe T, Tokumaru T, Takagi H, Nakazato H, Lloyd KO. Expression of Lewis a, Lewis b, Lewis $\mathrm{x}$, Lewis y, sialyl Lewis a, and sialyl Lewis $\mathrm{x}$ blood group antigens in human gastric carcinoma and in normal gastric tissue. Cancer Res 1989;49:745-52

26. Sipponen P, Hyvärinen H, Seppälä K, Blaser MJ. Pathogenesis of the transformation from gastritis to malignancy. Aliment Pharmacol Ther 1998;12 Suppl 1:61-71.

27. Stolte M, Eidt S. Prevalence of lymphoid follicles and aggregates in Helicobacter pylori gastritis in antral and body mucosa. J Clin Pathol 1993;46:832-5.

28. Taylor DE, Rasko DA, Sherburne R, Ho C, Jewell LD. Lack of correlation between Lewis antigen expression by Helicobacter pylori and gastric epithelial cells in infected patients. Gastroenterology 1998;115:1113-22.

29. Torrado J, Correa P, Ruiz B, Bernardi P, Zavala D, Bara J. Lewis antigen alterations in gastric cancer precursors. Gastroenterology 1992;102:424-30.

30. Umlauft F, Keeffe EB, Offner F, Weiss G, Feichtinger H, Lehmann E, Kilga-Nogler S, Schwab G, Propst A, Grussnewald K, Judmaier G. Helicobacter pylori infection and blood group antigens: lack of clinical association. Am J Gastroenterol 1996;91:2135-8.

31. Warren JR. Gastric pathology associated with Helicobacter pylori. Gastroenterol Clin North Am 2000;29:705-51.

32. Wyngaarden JB, Smith LH Jr. Tratado de medicina interna. $18^{\mathrm{a}}$ ed. Rio de Janeiro: Guanabara Koogan; 1990. v.1, p.1448.

33. Yaron N, Fraser G, Delpre G, Neeman A, Leiser A, Samra Z, Scapa E, Gilon E, BarShany S. Helicobacter pylori and blood groups. Am J Gastroenterol 1996;91:101-4.

34. Yoshida N, Granger DN, Evans DJ Jr, Evans DG, Graham DY, Anderson DC, Wolf RE, Kvietys PR. Mechanisms involved in Helicobacter pylori-induced gastritis. Gastroenterology 1993;105:1431-40.

Recebido em 19/2/2002 Aprovado em 24/8/2002. 